\title{
Constructing conceptual frameworks in social science research
}

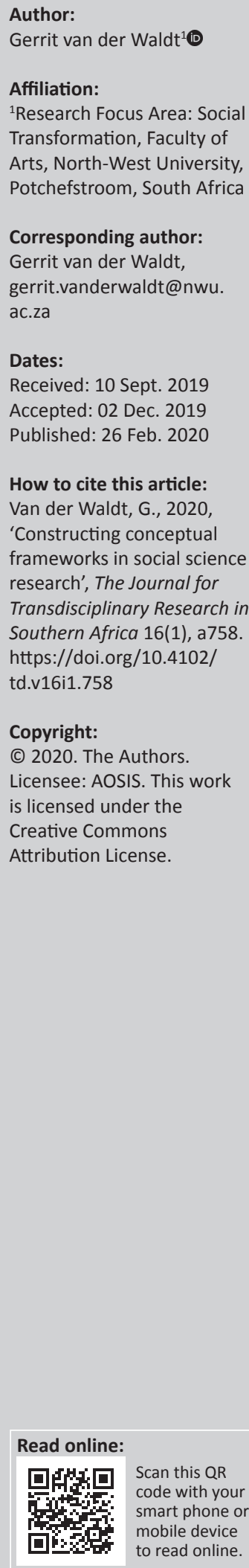

Research in the social sciences is concerned with complex social behaviour, group dynamics and unique human settings. Researchers have different patterns of thought and modes of thinking. As such, they often use different words to explain phenomena, thereby causing conceptual confusion. This article explains how conceptual frameworks can help overcome such confusion by serving as visual organising tools and mental maps to direct and guide research. By using a descriptive approach, the article aims firstly to outline the necessity, purpose, nature and scope of conceptual frameworks in social science research and, secondly, to provide a 'how-to' guide on the design of such a framework by exploring a practical example. The results illustrate conclusively the significant contribution that conceptual frameworks can and should make in social science research.

Keywords: concepts; constructs; conceptual framework; social sciences; theoretical framework; research; conceptualisation; literature review.

\section{Introduction}

Probably, one of the deepest frustrations of candidates engaged in postgraduate research in the social sciences is having to sift through a vast array of literature for relevant information on their topic. Furthermore, candidates will often get feedback on their proposals from their supervisors advising them that their efforts lack sound conceptual frameworks. This raises several questions beforehand: what is a conceptual framework? Why should it be regarded as an integral part of research and how does it guide a literature review? How should such a framework be constructed? Lack of clear answers to these questions generally leaves researchers adrift. Such a cognitive deficiency is even more acute in qualitative research involving the social sciences where, as Tilly and Goodin (2006:2) put it, 'it all depends ...'. Social science research can be defined as the conventions and methods scholars follow to comprehend, explain and predict the social world. In this regard, a comprehensive conceptual framework can function as an invaluable organising tool, focal point, mental map and blueprint for the entire study. A study without a sound conceptual framework typically lacks focus, contains irrelevant theory and suffers from weak methodological arguments.

Scholars such as Maree (2012:42, 212) and Ravitch and Riggan (2017:136) regard conceptual frameworks as the 'key part' of a research project as well as a key success factor in the approval of research manuscripts. There is clear evidence of research methodological textbooks' significance and contribution to the research process. However, these sources often only make a cursory mention of the conceptual frameworks and offer limited insight into its uses within research, let alone provide guidelines on to how to construct such a framework. Given this limitation, the purpose of the present article was twofold: firstly, outline the necessity, purpose, nature and scope of conceptual frameworks used in social science research; secondly, provide a 'how-to' guide on designing such a framework by exploring a practical example.

\section{Conceptual frameworks in social science research: A contextual and conceptual orientation}

Social scientists are typically engaged with highly ambiguous sense-making designs. Social science research is not usually conducted under fixed laboratory conditions (Flick 2014:33). Therefore, findings seldom neither conform neatly to expectations nor are linear or isolated easily (Ravitch \& Riggan 2017:108; Williams 2003:1). Social science research is concerned with complex social behaviour, group dynamics and unique human settings, such as culture, socio-economic status and educational background (Ritchie et al. 2014:13). In this regard, Erickson (cited in Ravitch \& Riggan 2017:83) argued that 'human interaction is not rocket science - it is far more 
complicated ...!' A critical component of human interaction is the study of verbal (language), and non-verbal and written engagement. Erickson (cited in Ravitch \& Riggan 2017:83) argued that language has multiple formal and informal meanings and is 'astonishingly complex'.

In scientific writing, scholars ascribe particular meaning to words, as Wilson (1971:129) explained, 'the conceptual equipment of people differs'. This realisation also leads Hornby (cited in Imenda 2014:188) to point out that defining concepts is 'not an innocent exercise'. People use different words to explain phenomena or describe emotions; they have different patterns of thought and modes of thinking. Such a variety may cause conceptual confusion. For example, the question arises about the difference between words such as 'concepts', 'constructs' and 'variables' often used in social science research. Therefore, it is necessary to clarify the meaning of 'concept' briefly compared to other words often used in scholarly work. Such clarification is critical to grasp the meaning of concepts as used within conceptual frameworks. Clarification of concepts is furthermore essential as accentuated by qualitative schools of thought, such as interpretivism and constructionism (Ritchie et al. 2014:12-13).

According to Lauffer (2011, cited in Saunders et al. 2015:39), the term 'concept' refers to 'a mental image or abstraction of a phenomenon'. In its broadest sense, a concept summarises ideas or observations about the characteristics of a mental image about a phenomenon. Maree (2012:34) stressed the importance of clarifying concepts derived from the title of a study by means of a thorough literature review. Silverman (2005:9) and Leggett (2011:3), in turn, stated that the notion that 'concept' has progressive levels of abstraction. Concepts such as 'table', 'window' and 'door' have extremely low levels of abstraction and are thus relatively simple to define. However, concepts with a high degree of abstraction such as 'personality' are difficult to visualise and define. Such abstract concepts are typically referred to as 'constructs'. Examples of constructs are 'leadership', 'ethics', 'democracy', 'welfare', 'performance', 'motivation' and 'anxiety'.

A clear definition of the above-mentioned constructs is not possible without a particular theoretical disposition. Constructs are thus heavily theory-laden (Kumar 2014:57). A definition of the construct 'religion', for example, is only possible if particular theoretical attributes are clarified, such as doctrines, scriptures, rituals and hermeneutics, which combinedly constitute a specific religion. The definition of 'religion' is also highly case-dependent; in other words, its meaning depends on the societal context. Such a set-up includes cultures, belief systems, traditions, values and norms that characterise followers of a particular religion. In light of such complexity, Miles and Huberman (1994:17) referred to constructs as 'intellectual bins' that define and show the interrelationship between the key concepts.

Conceptualisation entails building the level of sophistication to define concepts - from elementary to comprehensive
(Kumar 2014:57). The level of sophistication is reached by indicating how different scholars add characteristics, elements, dimensions and attributes to a concept. The researcher should finalise the development of key concepts with a comprehensive working definition that will be applicable to the particular study. Conceptualisation is thus broader than mere definition and should produce an agreedupon meaning (i.e. through adequate scholarly consensus) for concepts guiding a study. It should be evident that conceptualisation essentially does not concern questions of facts, value, meaning of words or its definition. The focus is rather about the usage of words in particular settings. As Ravitch and Riggan (2017:7) argued, 'The definition is far more important than the label'.

According to Welman and Kruger (1999:13), the term 'variable' refers to 'a characteristic or an attribute of the study object that varies', which implies at least two possible values. Examples of variables are: scores on a corruption index, level of performance on a measurement instrument scale or participants' gender and age demographics. The mentioned elements are incorporated in hypotheses to measure the correlation between a dependent and an independent variable (Thomas \& Smith 2003:11). Variables and operational definitions go hand in hand (Somekh \& Lewin 2011:46). Operational definitions in particular identify how the variables are measured for the purposes of the research. An operational definition should identify how the variable is calculated or recorded as a numeric value (Asher 1984:187).

\section{Utilising conceptual frameworks in social science}

An extensive literature survey revealed at least two different perspectives or applications of conceptual frameworks in research within the social sciences.

Based on the first perspective, scholars, such as Miles and Huberman (1994:23), Jacard and Jacoby (2010:54) and Ravitch and Riggan (2017:153), view a conceptual framework as a visual representation of a study's main theoretical tenets or concepts. Such a framework is usually introduced in the form of a graphical or schematic diagram depicting the key concepts and their relationships. In this view, a conceptual framework is required at the outset of a research project to identify key concepts, conceptualise these and indicate their interrelationship. Typically, such depiction is performed graphically as well as in the narrative form (Maree 2012:220). Miles and Huberman $(1994: 18,20)$ referred to this process as 'intellectual sorting work' and argued that it should be portrayed visually, allowing researchers to 'lay out sets of relationship to explore and make sense of'.

Maxwell (2005:35), in turn, referred to the above-mentioned visual frameworks as 'concept maps', which are the elements the researcher must 'construct'. He explained: 'A conceptual map incorporates pieces that are borrowed from elsewhere, but the structure, the overall coherence, is something that 
you build, not something that exists ready-made' (Maxwell 2005:47). In the same vein, Marshall and Rossman (2006) regarded a conceptual framework as a 'visual map' resulting from a thorough literature review. Maree (2012:221) pointed out that such a map is tentative and will change during the course of the study as new insight emerges from a robust literature review. Tracy (2013:97) held the same view and regarded a conceptual framework as synonymous with keywords in a research proposal. Green (2014:36) and Ravitch and Riggan (2017:153) cautioned, however, that a visual conceptual framework should not only be regarded as a product (i.e. a tick box exercise for postgraduate candidates) but also a process - an effort to direct the related research processes.

The second application or perspective states that conceptual frameworks should be regarded as the mental map that connects the various dimensions of the research process such as the researcher's a priori knowledge and interests, the literature survey, theory, methods, data analysis and findings. In this regard, Maxwell (2005:33) defined a conceptual framework as 'the system of concepts, assumptions, expectations, beliefs, and theories that supports and informs your research'. Miles and Huberman (1994:18) considered such a framework as the entire 'idea context' for the study.

Based on the above view, Ravitch and Riggan (2017) defined a conceptual framework as:

[T] he identification of presumed relationships among key factors or constructs to be studied, and the justification for these presumptions may come from multiple sources such as one's own prior research or 'tentative theories' as well as established theoretical or empirical work found in the literature. (p. 10)

According to this definition, a conceptual framework comprises at least three core dimensions, namely, personal interest of the researcher, topical (similar or relevant) research (based on an extensive literature review) and a theoretical framework. The problem statement of a study presents the context and the issues that prompted the researcher to conduct the study. Especially, in cases of research involving multidisciplinary projects, broad conceptualisation of the problem is essential. This implies breaking down and converting different research ideas into a common interpretation among team members.

The first perspective (visual representation) thus only implies identifying keywords (i.e. key concepts and related concepts as these appear in the title) and the visual mapping of the interrelationship between these elements. In contrast, the second perspective (mental map) regards a conceptual framework as the overall design of the research project. Such a map includes the following elements: personality and interests of the researcher, the research questions, methodology, methods, data analysis and findings. Thus, the second perspective entails a much broader view on a conceptual framework.
Based on the exposition above, there is evidently no clear-cut definition and application model for conceptual frameworks. Researchers may easily fall into the trap of entering into a semantic debate with other scholars. I certainly do not wish to add to the apparent confusion in this regard. Fortunately (or unfortunately), there is no Pope in science (á la Karl Popper 1963) to judge whether a particular position is 'right' or 'wrong'. One should, however, be aware of the pitfalls of oversimplification and reductionism by attaching complex notions to conceptual frameworks. For the purposes of this article, I base my working definition of conceptual frameworks on the first perspective. However, later, in the article, I will illustrate, through a practical example, how to incorporate aspects of the second perspective in the research process. My working definition is based on a synopsis of the attributes and contributions of a conceptual framework, namely:

- serving as an 'organising instrument' (Ravitch \& Riggan 2017:8)

- functioning as a 'sorting and learning tool' (Miles \& Huberman 1994:20)

- being the thought-experiment aspect of a 'speculative model-building exercise' (Maxwell 2005:38)

- functioning as a 'mental map' to direct and focus a literature review (Ravitch \& Riggan 2017:15)

- providing an 'interpretative approach to social reality', thereby aiding understanding (Jabareen 2009:51)

- supporting the argument for the study's significance and identifying the relevant theory (Marshall \& Rossman 2006:73)

- providing a 'visual illustration' of how concepts and constructs interconnect (Jarvis 1999:45; Tracy 2013:97).

\section{The significance of literature reviews in constructing conceptual frameworks}

Postgraduate candidates in social sciences are often told to read extensively. The expectation is that this 'reading' will become the basis of the literature review. Candidates tend to become overly anxious about this rather ambiguous, openended and seemingly never-ending task. This apprehension raises several questions. Where should they start? What are the most important and authoritative texts? How many books must be read and when is it sufficient? The result is that candidates begin to read abstracts of articles and open books, scanning through the table of contents to determine whether the publication is 'relevant' or not. Then, they begin transcribing content in the hope that it is significant for the study. However, the criterion or yardstick to use when determining the relevance of the content of textbooks or scholarly articles remains largely elusive.

Paulus, Lester and Demster (2014:49) stated that a literature review is important to situate the study's key concepts within a discipline's larger context, in order to join the ongoing conversation among a community of scholars. The literature review also guides the conceptualisation of key terms. 
Welman and Kruger (1999:253) stated that the literature review is essential to determine the 'current state of knowledge' about the research title. It is thus expected that researchers in the social sciences critically read the peerreviewed studies related to their topic and identify the theories aligned with their study (Somekh \& Lewin 2011:17).

A conceptual framework should be regarded as both the result and focus of a literature review. As a result of a literature review, the researcher has to consult literature to: (1) identify relevant and related concepts, (2) determine the potential connections (interrelationships) between these concepts and (3) identify suitable theory(-ies) by which to embed the study in a particular theoretical perspective. A preliminary (draft) conceptual framework designed before the commencement of the research also provides focus for a literature review. In other words, instead of engaging all the available literature on a topic, the researcher focusses on relevant literature based on the concepts identified in the framework. The scope of the review is thus limited to the suitability and relevance of literature instead of attempting to outline a broad, generalised review (cf. Hart 2001:23; Silverman 2005:296). Naturally, the approach differs from grounded theory where the researcher refrains from conceptualisation as the development of concepts is precisely the focus of research. The researcher thus works without pre-concepts, which makes the conceptual work inductive and corresponds to the hermeneutic nature of research in social sciences.

\section{The interface between conceptual and theoretical frameworks}

The literature does not always delineate clearly between theoretical and conceptual frameworks. There are generally three perspectives evident in a relationship between conceptual and theoretical frameworks:

- Firstly, conceptual and theoretical frameworks are viewed as synonymous (Maxwell 2005; Saunders et al. 2015:36).

- Secondly, a conceptual framework is considered as much broader in scope than a theoretical framework (Eisenhart 1991:205; Ravitch \& Riggan 2017:137).

- Thirdly, a theoretical framework is understood as part of a conceptual whole (Imenda 2014:189; Jacard \& Jacoby 2010:78; Kumar 2014:57).

Closer inspection of the above-mentioned perspectives indicates that authors ascribe a particular meaning to the notion of 'theory' (as applied in theoretical frameworks). Scholars who regard theoretical frameworks as broader than conceptual frameworks seemingly understand 'theory' in terms of meta-, grand- or macro-level theory or as a theoretical model in which the study is imbedded (cf. Maree 2012:42). This implies that a conceptual framework is rooted in the research traditions, paradigms and approaches of a particular discipline such as (Van der Waldt 2017:186):

- phenomenology

- grounded theory
- ethnomethodology

- symbolic interactionism

- feminism

- postmodernism.

Scholars who view theoretical frameworks as part of conceptual frameworks understand theory in terms of a micro-range where it informs specific concepts or constructs, such as motivation theory, leadership theory and organisational theory. In this regard, Kelly (2010) argued that micro-range theories guide research in at least four ways:

- provides a contextual orientation for the study by focusing attention on the specific aspects under investigation

- serves as instrument to conceptualise and classify concepts and constructs

- summarises what is already known about the object of study, including empirical generalisations, and systems of relationships between propositions; also pinpoints gaps in existing knowledge

- predicts results or findings of research. (p. 286)

In this latter sense, theoretical frameworks may also refer to existing established theories or researchers' own theorising, for example, assumptions, presuppositions, premises or hypotheses (Sutton \& Staw 1995:373; Torraco 1997:115).

Apart from the first perspective, namely, that conceptual and theoretical frameworks are synonymous, I concur fully with both the second and third perspectives mentioned previously, depending on the definition of the concept of 'theory'. A conceptual framework is informed by theory to imbed the study philosophically, epistemologically and methodologically (second perspective). However, such a framework is also broader than a theoretical one (third perspective). The reason is that concepts and constructs identified in the conceptual framework will guide the application of theory on a micro-level.

A study concerned with human resource management will therefore be imbedded in, for example, symbolicinteractionism and behaviourism as its grand, macro-level theory. Then, the study would narrow its focus to micro-level theory. This is performed to inform the main concepts and constructs of the study, such as theories of leadership, communication or group dynamics, and organisations. Theoretical frameworks are thus both broader and form part of (is smaller than) conceptual frameworks.

\section{Constructing a conceptual framework: Suggested 'how to' steps}

As there is no single, best format for making an argument, there is also no single 'right' way to construct a conceptual framework. As stated previously, a sound conceptual framework provides a clearly articulated point of reference from which the researcher can make sense of the dynamic nature of the research process. As new insight emerges and 
adjustments are made, the conceptual framework will remain the focal or the reference point.

The effective construction of a conceptual framework requires certain skills from the researcher, for example:

- contextual awareness by understanding the world as dynamic interaction of multiple events and trends

- general knowledge and meaning-making abilities

- logical reasoning and common sense

- basic understanding of the potential causal relationships between multiple variables

- a measure of linguistic acumen (e.g. suitably apply dictionary meanings of words and its usage in different social settings)

- model-building skills

- the ability to answer the 'what-if', 'what', 'how', 'where' and 'when' questions related to research topics and titles.

In the absence of some of the above-mentioned skills, researchers or 'emerging researchers' (e.g. postgraduate candidates) may simply brainstorm ideas with a more senior, experienced colleague or their supervisor.

The purpose of this section is to provide a practical reference point from which researchers in the social sciences can construct their own conceptual frameworks. The proposed steps to follow are expounded briefly below.

Step 1: Choose the topic. The topic describes the field of study, for example, public finance, project management or human resource management. Therefore, the topic should be within the researcher's field of interest and/or specialisation.

Step 2: Choose the title. Typically, a title should focus on the study and illustrate the relationship between variables, for example, 'the significance of leadership for organisational excellence', where 'leadership' and 'organisational excellence' are key constructs.

Step 3: Isolate the key concepts and/or constructs in the title. Identify the specific variables described in the literature and determine how these are potentially related.

Step 4: Do a literature review and identify related concepts and variables. Review relevant and updated research on the title of the study in general and the concepts and constructs in particular. Consult preferably peer-reviewed text books and established scientific journals because these are more reliable sources of information.

Step 5: Generate the conceptual framework. In this phase, the researcher should be in a position to construct at least a basic conceptual framework by using the information gathered from the literature review. The study's problem statement provides a reference for constructing the conceptual framework. The purpose of such a framework is to illustrate the research approach in graphical form to aid understanding of the research approach and design.
Causal relationships: The basis of constructing a conceptual framework is often using a cause-effect relationship. If the study involves this type of research, the goal is to prove such a relationship empirically. A cause-effect relationship typically involves two types of variables: independent and dependent. Cause-effect relationships frequently include several independent variables that affect the dependent variable (Welman \& Kruger 1999:13).

Design components: The basic components are boxes, arrows and lines. It is advisable to create a box for each concept or construct. Then, arrows are inserted to indicate cause-effect relationships. Each arrow should start from the variable that has causal influence and point to the one being affected. Lines are used to indicate an expected correlation between two variables, but not necessarily of cause and effect. It should also be noted that conceptual frameworks do not have to be limited to independent and dependent variables. Other types of variables can be incorporated as well (e.g. moderator, mediator and control).

Once the conceptual framework is nearing completion, the researcher can commence scientific research that will prove the illustrated relationships. Any number of qualitative and quantitative research methods can be used for data collection, including literature reviews, interviews and surveys.

To illustrate the steps in constructing a conceptual framework practically, the following example is used:

\section{Research title: Community perception regarding municipal service delivery efforts}

Based on the mentioned title, the following key concepts are evident: 'community', 'perception', 'municipality' and 'service delivery'. Figure 1 illustrates the most basic conceptual framework or visual map for these key concepts.

However, such a simple illustration is inadequate to guide the literature review effectively and operationalise the research objectives. Based on the typical expectations of a conceptual framework, this illustration cannot be considered as an adequately completed stage. It is therefore necessary to unpack or frame these concepts further. This could be performed by formulating and answering simple questions such as 'what to cover?' (in the literature review); 'who to approach?'; the 'theoretical framework' and 'variables'; and 'when?' In the process, the content of the concepts will populate rapidly into more detail and the broader design of the study will emerge. In the tabular columns below, the respective concepts (1-4) associated with the title used as examples are expounded in more detail. This is performed by answering the mentioned questions, thus placing the study as a whole in sharper focus.

\begin{tabular}{|c|c|} 
Community $^{1}$ & Service delivery $^{3}$ \\
\hline Perception $^{4}$ & Municipality \\
\hline
\end{tabular}

FIGURE 1: Basic conceptual framework. 
The content of each dimension (i.e. right columns) is open for interpretation based on the particular a priori knowledge of the researcher, research approach and methodology followed, as well as the thoroughness of the literature review. The content merely serves as a guideline for researchers embarking on a study of similar nature.

Tables 1-4 explain in detail the attributes related to the four concepts, namely, Community, Municipality, Service delivery and Perception, as depicted in Figure 1.

The example expounded above clearly focusses on the study and could be used as a blueprint for the design of the study as a whole, including:

- focussed literature review investigating the identified concepts, constructs and variables

- analysis of the case study and processing of the units of analysis
- relevant theoretical framework: macro- and micro-level theory per concept or construct

- formulation of research questions - directed by framing questions in the columns

- choice of instrumentation for data collection.

Then the conceptual framework can be used as a focal point in the remaining steps of the research process. This includes the following:

- Identifying a grand or macro-level theory in which to embed the study and pinpointing smaller theories to probe the correlation and interrelationship between concepts (i.e. theoretical framework). Based on the expounded example, this framework would integrate theories related to service delivery and organisational (municipal) excellence.

- Embedding and anchoring constructs within the identified theories.

\section{TABLE 1: Framing concept 1 - Community.}

\begin{tabular}{|c|c|}
\hline Variable & Attributes \\
\hline What to cover? & $\begin{array}{l}\text { - Definitions of 'society' and 'community' } \\
\text { - Typology of community } \\
\text { - Demographical statistics: occupations and incomes; transport and communication; traditions; and resources, including infrastructure and facilities } \\
\text { - Community history: How long has the community been in existence and how was it founded? When did different social, economic, ethnic and cultural } \\
\text { groups settle in the community? How has the community changed over time and what has caused those movements? } \\
\text { - Community structure: How many people and households are there in the community? What is the gender and the age structure of the } \\
\text { community? What different social, economic, ethnic and cultural groups live in the community? How are these groups defined? Where do } \\
\text { these diverse groups live? } \\
\text { - The needs, aspirations and conditions of the community } \\
\text { - Community leaders, functioning of ward committees, community development workers and local decision-making structures } \\
\text { - Livelihoods: What are the different activities of households in the community to support their livelihoods? Who is involved in those activities } \\
\text { (men or women, young or old, different social and economic groups) and how many people and households depend on them? When do those activities } \\
\text { take place (time of day or month or season) and where? } \\
\text { - Local institutions: What formal organisations and associations are involved in the community? What rules, regulations and customs are there? Who is } \\
\text { affected by these and how? } \\
\text { - Community infrastructure: What services are available to the community, such as transport, electricity and water supply, markets, agricultural extension, } \\
\text { health and education? Who has access to these services? How expensive is such infrastructure? } \\
\text { - Resources: What are the principal natural resources available to the community? Who uses them and how? Where are these located? }\end{array}$ \\
\hline $\begin{array}{l}\text { Whom to approach for } \\
\text { primary and secondary } \\
\text { data collection? }\end{array}$ & $\begin{array}{l}\text { Primary: } \\
\text { - Households (e.g. homeowners) } \\
\text { Secondary: } \\
\text { - Ward councillors and ward committee members } \\
\text { - Traditional leaders } \\
\text { - Community development workers } \\
\text { - Formal and informal community-based organisations - ranging from church groups to youth clubs and burial societies } \\
\text { - Local businesses } \\
\text { - Prominent community development leaders } \\
\text { - Other service providers operating in the community } \\
\text { - The local media (e.g. community newspapers) }\end{array}$ \\
\hline Theoretical framework & $\begin{array}{l}\text { - Target or receiver group theory } \\
\text { - Knowledge gap theory } \\
\text { - Muted group theory } \\
\text { - Spiral of silence theory } \\
\text { - Social exchange theory } \\
\text { - Expectancy value theory } \\
\text { - Social penetration theory }\end{array}$ \\
\hline Variables & $\begin{array}{l}\text { - Community perception per income group } \\
\text { - History, including impact of periodic events such as local policies } \\
\text { - Spatial characteristics of the community } \\
\text { - Seasonal and historical trends and events } \\
\text { - Importance and accessibility of services in the community } \\
\text { - Community strengths, weaknesses, opportunities and threats } \\
\text { - Priority outcomes for the community }\end{array}$ \\
\hline
\end{tabular}


TABLE 2: Framing concept 2 - Municipality.

\begin{tabular}{ll}
\hline Variable & Attributes \\
\hline What to cover? & - Local governance context: political dynamics and ideology, \\
social and demographical realities, economic conditions, \\
development trajectory, historical realities, social cohesion \\
or national identity \\
- System of governance - cooperative governance and \\
Intergovernmental Relations (IGR) \\
- Municipal structures \\
- Statutory and regulatory obligations \\
- Municipal capacity and competency \\
- Municipal management praxis and best practice \\
- Performance monitoring and evaluation \\
- Case study: JB Marks Local Municipality: basic service \\
delivery departments, for example, water supply, electricity, \\
sewerage, sanitation, refuse removal, basic health services, \\
municipal roads and street lighting \\
- Theories on the role of the state in modern society: moral \\
obligations, political and legal responsibilities, administrative \\
responsibilities, and responsibilities of political \\
representatives and public officials \\
- Social contract theory \\
- $\begin{array}{l}\text { Theoretical } \\
\text { framewolic choice theory }\end{array}$ \\
- Organisation theory and organisational information theory \\
- Adaptive structuration theory \\
- Contingency theory \\
participation
\end{tabular}

TABLE 3: Framing concept 3 - Service delivery.

\begin{tabular}{|c|c|}
\hline Variable & Attributes \\
\hline \multirow[t]{15}{*}{ What to cover? } & - Typology of basic or essential municipal services \\
\hline & - Municipal services versus functions \\
\hline & - Demand-driven versus supply-driven service delivery \\
\hline & - Levels and standards of services \\
\hline & $\begin{array}{l}\text { - Service delivery priorities: demographical realities, } \\
\text { priority settings }\end{array}$ \\
\hline & $\begin{array}{l}\text { Key service delivery challenges: infrastructure } \\
\text { backlogs, skills and capacity shortage, unfunded } \\
\text { mandates from national and provincial government, } \\
\text { new and varied legislation, corruption and nepotism, } \\
\text { low municipal tax base, service ethos, consultant- } \\
\text { driven delivery }\end{array}$ \\
\hline & - Political dynamics and service delivery protests \\
\hline & $\begin{array}{l}\text { - Structures for service delivery: departmentalisation, } \\
\text { division of work }\end{array}$ \\
\hline & $\begin{array}{l}\text { - Management dimensions: strategic, tactical and } \\
\text { operational planning, resource allocation, work } \\
\text { procedures, control measures, delegating authority, } \\
\text { coordination, reporting and 'back-office' engineering } \\
\text { for service delivery }\end{array}$ \\
\hline & $\begin{array}{l}\text { - Alternative service delivery mechanisms: public- } \\
\text { private partnerships, municipal service } \\
\text { partnerships, outsourcing, commercialisation }\end{array}$ \\
\hline & $\begin{array}{l}\text { - Customer care, professionalism and Batho Pele in } \\
\text { service delivery }\end{array}$ \\
\hline & - Complaint procedures \\
\hline & $\begin{array}{l}\text { - Measuring the success of service delivery: } \\
\text { performance, quality, efficiency, economy, } \\
\text { effectiveness and productivity; the use of performance } \\
\text { management systems }\end{array}$ \\
\hline & $\begin{array}{l}\text { - Implementation of service delivery improvement } \\
\text { programmes }\end{array}$ \\
\hline & $\begin{array}{l}\text { - Role of technology (e-Govt, ICT, SMART cities) in } \\
\text { service delivery }\end{array}$ \\
\hline \multirow[t]{9}{*}{ Theoretical framework } & - Public institutional theory \\
\hline & - Theories on public accountability \\
\hline & - Public good theory \\
\hline & - Social contract theory \\
\hline & - Decision theory \\
\hline & - Rational choice theory \\
\hline & - Public value theory \\
\hline & - Social exchange theory \\
\hline & - Diffusion of innovation theory \\
\hline
\end{tabular}

TABLE 4: Framing concept 4 - Perception. ${ }^{1}$

\begin{tabular}{|c|c|}
\hline Variable & Attributes \\
\hline Theoretical framework & $\begin{array}{l}\text { - Theory of human cognisance, awareness, } \\
\text { interpretation of sensory information, formation of } \\
\text { opinion and impressions connected to a person's } \\
\text { concepts, expectations and knowledge, and } \\
\text { influence of perception } \\
\text { - Theory of local democracy and public participation } \\
\text { - Theory of human engagement dynamics } \\
\text { - Communication theory }\end{array}$ \\
\hline $\begin{array}{l}\text { How to measure? (method } \\
\text { of data collection) }\end{array}$ & $\begin{array}{l}\text { - Snow-ball sampling of households in randomly } \\
\text { sampled municipal wards, representing total } \\
\text { population in the municipal community } \\
\text { - Face-to-face interviews through an interview } \\
\text { schedule guided by five-point Likert-scale } \\
\text { questions } \\
\text { - Use of two trained field workers well versed in the } \\
\text { dominant local languages }\end{array}$ \\
\hline Where? & $\begin{array}{l}\text { - At houses of participants, for example, every } \\
\text { 10th house in street blocks per municipal ward }\end{array}$ \\
\hline When? & - Saturday mornings when homeowners are at home \\
\hline $\begin{array}{l}\text { Variables (influencing } \\
\text { factors)* }\end{array}$ & $\begin{array}{l}\text { - Perception influenced by participants' age, } \\
\text { gender, employment status, social status, culture, } \\
\text { ethnicity, race, belief systems and educational } \\
\text { background } \\
\text { - Influenced by legitimacy of government in } \\
\text { general and the JB Marks Local Municipality in } \\
\text { particular } \\
\text { - Prior experiences of community members } \\
\text { - Extent or level of interaction with municipal services } \\
\text { - Language barrier - interpreter, training of field } \\
\text { workers } \\
\text { - Willingness or lack of willingness to express opinions } \\
\text { openly because of fear of intimidation - involving } \\
\text { research ethics: anonymity and confidentiality, and } \\
\text { consent form } \\
\text { - Political instability/stability of the municipal } \\
\text { ward: prevalence of violent protests and service } \\
\text { boycotts } \\
\text { - } \text { *The interview schedule should provide for these } \\
\text { variables by posing follow-up questions. Such a } \\
\text { schedule is also significant for data analysis. }\end{array}$ \\
\hline
\end{tabular}

- Determining suitable sources and methods of data collection.

- Analysing data based on the conceptual framework (correlation, relationships).

- Developing grounded theory (if relevant for the nature of the study) derived from the findings.

By incorporating the outlined detail, it is possible to construct a far more comprehensive conceptual framework, as depicted in Figure 2.

The schematic illustration in Figure 2 presents the researcher with a clear map to direct the literature review and design the content of theoretical chapters. The dimensions and variables associated with each concept will have to be addressed in these theoretical chapters (e.g. headings and subheadings) for an adequate conceptualisation of the main concepts and constructs. Such an exploration must be embedded in theory(-ies) at both macro- and micro-levels.

It should be noted again that conceptual frameworks can be reconceptualised and modified based on the perspectives and insights that were unavailable when the framework was 1.For consistency, "perception' is referred to as a concept, although, technically, it is regarded as a construct. 


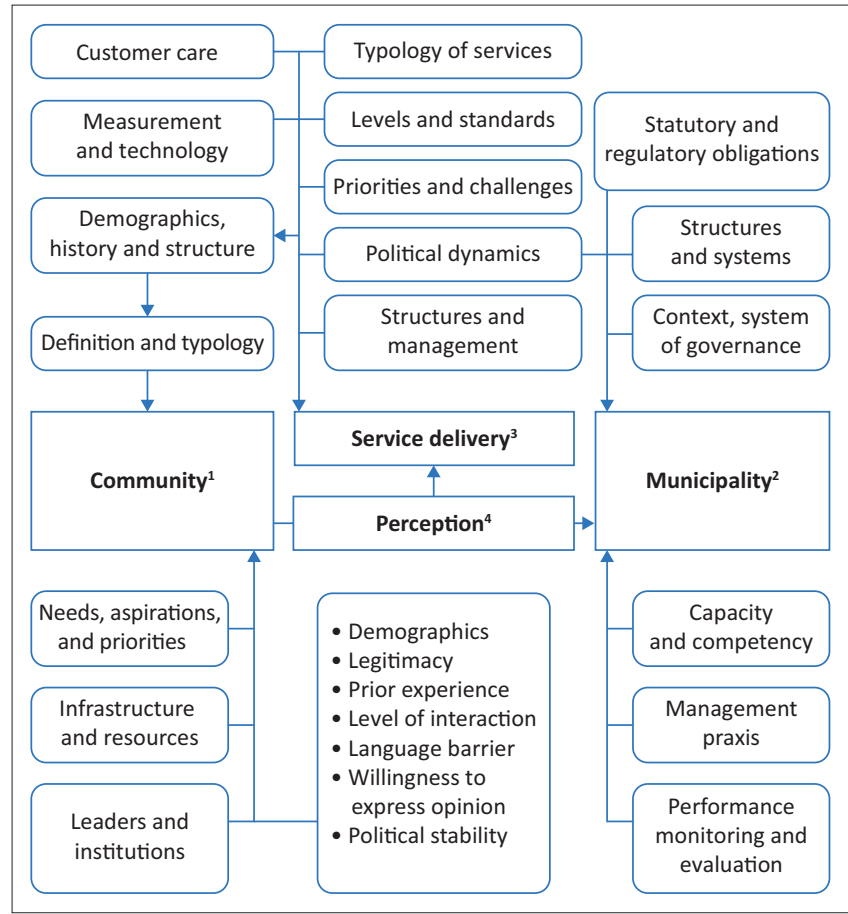

FIGURE 2: Example of a comprehensive conceptual framework.

first constructed. Such reconstruction is consistent with the fundamental premise that research in the social sciences is non-linear, evolutionary and dynamic.

\section{Conclusion}

The purpose of this article was to outline the contours of conceptual frameworks as applied in social science research and practically illustrate possible steps to construct such frameworks. It is evident that conceptual frameworks mainly serve the purpose of directing literature reviews and helping embed the study in theories both at macroand micro-levels.

Constructing conceptual frameworks is not easy at first. However, with exercise and experience, it will add significant value to any research within the social sciences. As Tracy (2013:v) rightly remarked, 'Anything worth doing well is worth doing badly in the beginning'.

\section{Acknowledgements Competing interests}

The author has declared that no competing interest exists.

\section{Author's contributions}

I declare that I am the sole author of this research article.

\section{Ethical consideration}

This article followed all ethical standards for a research without direct contact with human or animal subjects.

\section{Funding information}

This research received no specific grant from any funding agency in the public, commercial or not-for-profit sectors.

\section{Data availability statement}

Data sharing is not applicable to this article as no new data were created or analysed in this study.

\section{Disclaimer}

The views and opinions expressed in this article are those of the author and do not necessarily reflect the official policy or position of any affiliated agency of the author.

\section{References}

Asher, H.B., 1984, Theory-building and data analysis in the social sciences, University of Tennessee Press, Knoxville, TN.

Eisenhart, M., 1991, Conceptual frameworks for research circa 1991: Ideas for a cultural anthropologist; implications for mathematics education rese, Psychology of Mathematics Education, Blacksburg, VA.

Flick, U., 2014, An introduction to qualitative research, 5th edn., Sage, London.

Green, H.E., 2014, 'Use of theoretical and conceptual frameworks in qualitative research', Nurse Research 21(6), 34-38. https://doi.org/10.7748/nr.21.6.34.e1252 Hart, C., 2001, Doing a literature search, Sage, London.

Imenda, S., 2014, 'Is there a conceptual difference between theoretical and conceptual frameworks?', Journal of Social Science 38(2), 185-195. https://doi.org/10.1080/ 09718923.2014.11893249

Jabareen, Y., 2009, 'Building a conceptual framework: Philosophy, definitions, and procedures', International Journal of Qualitative Methods 8(4), 49-62. https://doi. org/10.1177/160940690900800406

Jacard, J. \& Jacoby, J., 2010, Theory construction and model-building skills: A practical guide for social scientists, Guilford, New York.

Jarvis, P., 1999, The practitioner-researcher: Developing theory from practice, JosseyBass, San Francisco, CA.

Kelly, M., 2010, 'The role of theory in qualitative health research', Family Practice 27(3), 285-290. https://doi.org/10.1093/fampra/cmp077

Kumar, R., 2014, Research methodology: A step-by-step guide for beginners, 4th edn., Sage, London.

Leggett, A., 2011, 'Constructs, variables and operationalization', in J.F. Hair, R.P. Bush \& D.J. Ortinau (eds.), Marketing Research within a Changing Information Environment, pp. 56-93, McGraw-Hill, Boston, MA.

Maree, J.G. (ed.), 2012, Complete your thesis or dissertation successfully: Practical guidelines, Juta, Cape Town.

Marshall, C. \& Rossman, G.B., 2006, Designing qualitative research, 4th edn., Sage, Thousand Oaks, CA.

Maxwell, J., 2005, Qualitative research design: An interactive approach, Sage, Thousand Oaks, CA.

Miles, M.B. \& Huberman, M.A., 1994, Qualitative data analysis: An expanded sourcebook, 2nd edn., Sage, Thousand Oaks, CA.

Paulus, T.M., Lester, J.N. \& Demster, P.G., 2014, Digital tools for qualitative research, Sage, London.

Popper, K.R., 1963, Conjectures and refutations: The growth of scientific knowledge, Basic Books, New York.

Ravitch, S.M. \& Riggan, M., 2017, Reason and rigor: How conceptual frameworks guide research, 2nd edn., Sage, London.

Ritchie, J., Lewis, J., Nicholls, C.M. \& Ormston, R., 2014, Qualitative research practice: A guide for social science students and researchers, 2 nd edn., Sage, London.

Saunders, M.N.K., Gray, D.E., Tosey, P. \& Sadler-Smith, E., 2015, 'Concepts and theory building', in L. Anderson, J. Gold, J. Stewart \& R. Thorpe (eds.), A guide to professional doctorates in business and management, pp. 35-56, Sage, London.

Silverman, D., 2005, Doing qualitative research: A practical handbook, 2nd edn., Sage, London.

Somekh, B. \& Lewin, C. (eds.), 2011, Theory and methods in social research, 2nd edn., Sage, London.

Sutton, R.I. \& Staw, B.M., 1995, 'What theory is not', Administrative Science Quarterly 40(3), 371-384. https://doi.org/10.2307/2393788

Thomas, A.R. \& Smith, P.J., 2003, Spotlight on social research, Pearson Education, New York. 
Tilly, C. \& Goodin, R.E., 2006, It depends: The Oxford handbook of contextual political analysis, Oxford University Press, Oxford.

Torraco, R.J., 1997, 'Theory-building research methods', in R.A. Swanson \& E.F. Holton (eds.), Human resource development handbook: Linking research and practice, pp. 114-137, Berrett-Koehler, San Francisco, CA.

Tracy, S.J., 2013, Qualitative research methods: Collecting evidence, crafting analysis, communicating impact, John Wiley \& Sons, London.
Van der Waldt, G., 2017, 'Theories for research in public administration', African Journal of Public Affairs 9(9), 183-202.

Welman, J.C. \& Kruger, S.J., 1999, Research methodology for the business and administrative sciences, Oxford University Press, Cape Town.

Williams, M., 2003, Making sense of social research, Sage, London.

Wilson, J., 1971, Thinking with concepts, Cambridge University Press, Cambridge. 